\title{
Perspectives on eco-water security and sustainable development in the Yangtze River Basin
}

\author{
Jun Xia ${ }^{1,2^{*}}$, Zhe $\mathrm{Li}^{3}$, Sidong Zeng ${ }^{3}$, Lei Zou ${ }^{2}$, Dunxian She ${ }^{1}$ and Dandong Cheng ${ }^{4}$
}

\begin{abstract}
The Yangtze River, the largest river in China, has been facing major challenges in massive flooding and eco-environmental health over the past decades. Sustainable socioeconomic development in the Yangtze River Basin depends on water and ecosystem security. This overview addresses eco-water security under the changing environment of the Yangtze River Basin. Looking forward to a healthy Yangtze River in the future, there are still uncertainties regarding how to assess and wisely manage the Yangtze River through a systematic, integrated approach applied to multiple dimensions, water, biodiversity, ecological services, and resilience, for the sustainable development of ecosystems and human beings. The Yangtze Simulator, an integrated river basin model powered by artificial intelligence and interdisciplinary science, is introduced and discussed, and it will serve as a robust tool for good governance of the Yangtze River Basin.
\end{abstract}

Keywords: Eco-water security, Environmental change, Sustainable development, Yangtze Simulator, Integrated management

\section{Introduction}

The world's large rivers and their basins are of great importance for providing indispensable services to support human well-being (Zalewski et al. 2016; Castello and Macedo 2016; Zalewski 2013). These large river basins feed human civilization, support growing populations, and constitute diverse landscapes and ecosystems (Best 2019). Nevertheless, large river basins have suffered irreversible and irreparable changes since the Industrial Revolution. The expansion of human activities in river basins for thousands of years has led to the occupation of large areas for human settlements, e.g. cities, towns, farmland for food production, dams and reservoir impoundments for water and energy supply, and waterways for trade, intake and sewers (Best 2019). Unprecedented

\footnotetext{
${ }^{*}$ Correspondence: xiajun666@whu.edu.cn

1 State Key Laboratory of Water Resources \& Hydro Power Engineering

Sciences, Wuhan University, Wuhan 430072, China

Full list of author information is available at the end of the article
}

growth of the human footprint in the world's large river basins has been changing all aspects of river basin ecosystems: landscape diversity, geo-morphology of river channels, hydrology, biogeochemistry and biodiversity (Ramachandra et al. 2018, 2020). In addition, accelerating global warming and the increasing occurrence of extreme climate events drastically manipulate or even degrade the ecosystem services of the world's large rivers (Denman et al. 2007), decreasing the value of these ecosystem services and their functioning in large river basins. Thus, the calls for sustainable development in the world's large river basins-to adapt to global climate change in support of the well-being of human society-have never been so urgent as in the past few decades.

The Yangtze River is called the mother river in China. Since the economic reform initiated in 1979, remarkable economic growth has been associated with large campaigns of exploitation in the Yangtze River Basin (Han et al. 2017; Chen et al. 2009). Under the impacts of climate change and land-use and cover change, the Yangtze 
River Basin faces a series of challenges. These include the degradation of aquatic ecosystems and water quality and increases in the frequencies of extreme floods or drought (Liu et al. 2020). While the past few decades have witnessed the apparent deterioration of the Yangtze River ecosystem, the public has called for the restoration of ecosystem services and the promotion of sustainable development (Yang et al. 2020,2016; Xu et al. 2018).

This overview addresses eco-water security and sustainable development in the Yangtze River basin under a changing environment. First, we review the current situation and problems of the eco-environment in the Yangtze River Basin. Then, we discuss the challenges of eco-water security in the Yangtze River. Finally, the Yangtze Simulator is introduced as an integrated modelling system for the evaluation of eco-water security in the Yangtze River Basin.

\section{Eco-environmental change in the Yangtze River and its consequences}

The Yangtze River, as the largest river in China and the third largest river in the world, plays a key role in both socioeconomic development and ecosystem services in China (Fig. 1). It rises in the Tanggula Mountains on the Plateau of Tibet and flows in a generally easterly direction to the East China Sea, traversing or serving as the border between 10 provinces or regions in China. It has a river basin area of approximately 1.8 million $\mathrm{km}^{2}$, approximately one-fifth of the land area of China. The discharge of the Yangtze River ranges between 2000 and $110,000 \mathrm{~m}^{3} \mathrm{~s}^{-1}$, with an average of $30,146 \mathrm{~m}^{3} \mathrm{~s}^{-1}$. Holding approximately one-third of China's population (400 million), the Yangtze River Basin has played a major role in the history, culture and economy of China. For thousands of years, the river has been used for water, irrigation, sanitation, transportation, industry, etc.

Over the past several decades, especially after the reform and opening-up of China in the late 1970s, the Yangtze River has been experiencing drastic environmental change under a number of anthropogenic stressors, including damming campaigns, anthropogenic pollution, the introduction of nonnative species, and sediment mining. These stressors have challenged the biological integrity and sustainable development in the river basin.

\section{Damming campaign for flood control and renewable energy}

Floods of the Yangtze River in central and eastern China occur periodically, causing considerable destruction of property and loss of life. Among the most recent major flood events are those of 1870, 1931, 1954, 1998, 2010, and 2020 (Feng 2011; Betts et al. 2006). Economic booms have resulted from damming on both the main stem and tributaries of the Yangtze River, initiated in the late 1970s. This campaign was launched partially to meet the growing needs of renewable electricity to support the emergence of the regional economy and sustained socioeconomic growth, and partially for flood control to

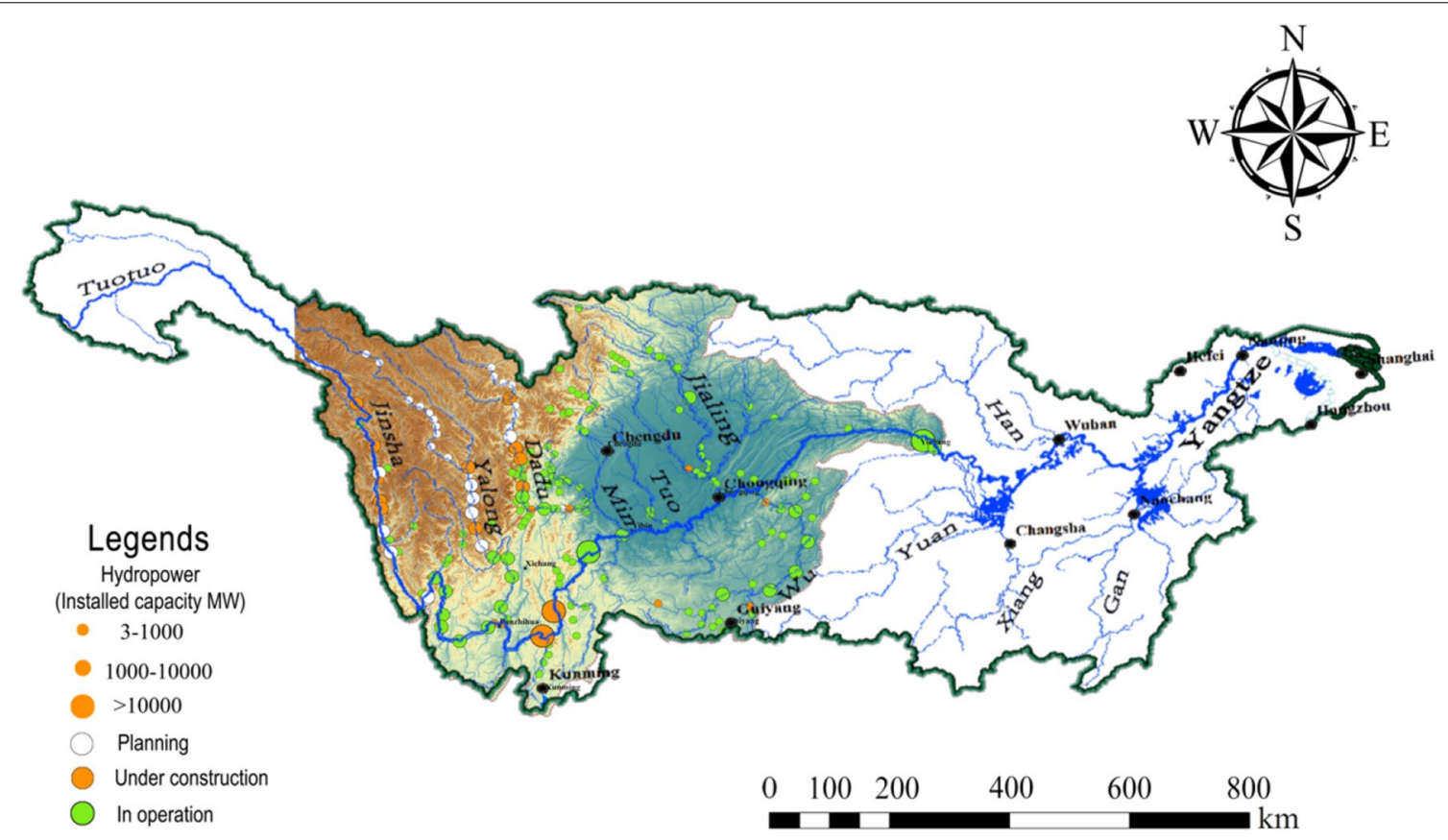

Fig. 1 Schematic diagram of the Yangtze River Basin in China, and the large-scale hydropower plants in the upper Yangtze River Basin 
secure downstream human settlements (Chen et al. 2016; Shi et al. 2019). At present, over 60,000 dams exist in the Yangtze main stem and tributaries. Over the past $2 \mathrm{dec}$ ades, large-scale hydropower cascade development on the upper reaches of the Yangtze River, symbolized by the Three Gorges Dam, has been increasing.

\section{Land use and cover change and urbanization for the growing population}

The Yangtze River Basin has witnessed accelerating urbanization and industrialization caused by the growing population and economic booms during the last 4 decades. A recent study by Li et al. (2020) showed that agricultural land, grassland, and unused land in the Yangtze River Basin decreased by 5.9\%, 1.0\%, and 17.4\%, respectively, from 1980 to 2015 . In contrast, human settlements-i.e. land for industry, towns, and cities-dramatically increased from nearly $2.0 \times 10^{4} \mathrm{~km}^{2}$ in 1980 to $4.8 \times 10^{4} \mathrm{~km}^{2}$ in 2015 .

\section{Climate change increased uncertainties in the hydrology of the Yangtze River}

Climate change gradually and evidently impacts the hydrological cycle in the Yangtze River Basin (Allan et al. 2013; Xia 2012). Meteorological records reveal a significant gradual increase in air temperature and precipitation in the upper Yangtze River, particularly in the source region (Wen et al. 2020; Xu et al. 2019; Chai et al. 2019). Increased frequencies of extreme events, such as severe floods and droughts, were also reported to be unavoidable in the middle and lower parts of the Yangtze River (Li et al. 2020; Ye et al. 2020). For example, severe floods impacted 8 provinces in the Yangtze River Basin in 2020, causing economic damage of more than 40 billion CNY (Fig. 2).

\section{Consequences and challenges for ecological sustainability in the Yangtze River Basin}

Recognizing the fact that the Yangtze River Basin plays vital roles in China's socioeconomic development, the
Yangtze River ecosystem has been suffering overwhelmed anthropogenic and climate change stresses, causing evident and shocking deterioration. For a period of time, "large-scale investment" and "large-scale development" have sounded alarms for the Yangtze River ecosystem. These include the development of the chemical industry and corresponding increases in domestic and industrial wastewater discharge, illegal wharf and sand mining, wetland shrinkage and land-use change, and habitat loss (Floehr et al. 2013; Qi et al. 2014; Han et al. 2018; Morgan and Waretini 2013). Increased anthropogenic pollution has decreased the water quality in the Yangtze River, especially in its tributaries and reaches in urbanized areas since the 1980s (Di et al. 2019; Sun et al. 2013; Li et al. 2018). This also caused accelerated eutrophication and increases in algal blooms in downstream lakes and ponds in the Yangtze River Basin, such as Donghu Lake (Wang et al. 2012), Taihu Lake (Xu et al. 2010), and Chaohu Lake (Le et al. 2010; Krueger et al. 2012). Aquatic biodiversity has drastically declined since the 1980 s as a result of damming and increases in anthropogenic pollution and river navigation (Wang and Huang 2020). The stocks of historically abundant, economically important fish species in the Yangtze River, such as black carp (Mylopharyngodon piceus), grass carp (Ctenopharyngodon idellus), silver carp (Hypophthalmichthys molitrix), and bighead carp (Aristichthys nobilis), were also reported to dramatically decline between 2000 and 2010 (Chen et al. 2009). In addition, climate change has shaped the Yangtze River Basin and its eco-environment, as well as its socioeconomic development (Gu et al. 2011). Simultaneously, the drastic decline in river biodiversity and ecosystem functioning did not stop this "rush" for economic development in the Yangtze River Basin over the past 10 years. The Yangtze River was declared "sick" and significantly limited in meeting the goals of sustainable development.

While the past decades witnessed a fast-growing economy and population expansion in the Yangtze River Basin, drastically increasing anthropogenic stresses have also been imposed on the Yangtze River ecosystem. All

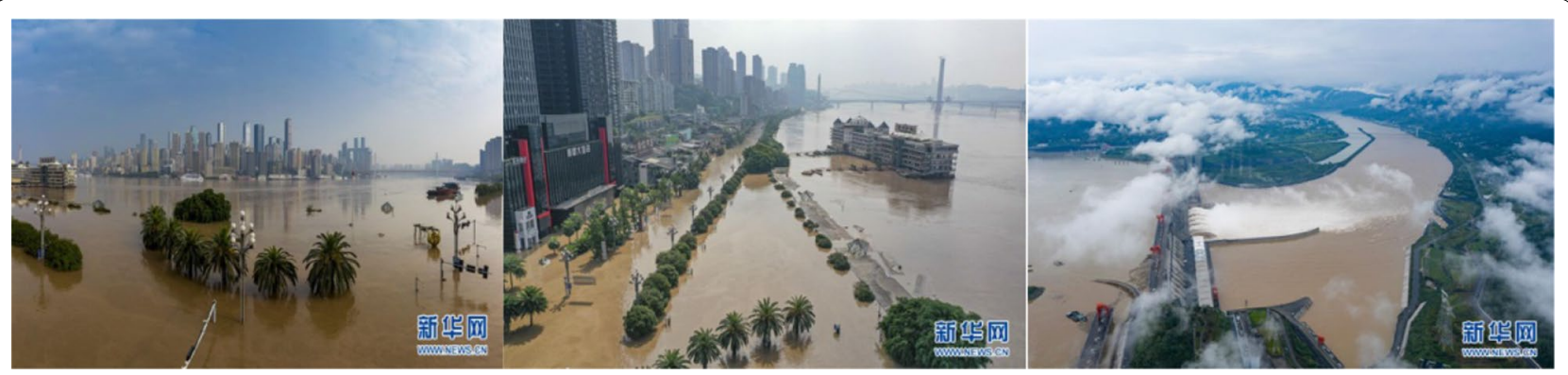

Fig. 2 Severe floods in the Yangtze River Basin in 2020 
these stresses shape the challenges of ecosystem sustainability in the Yangtze River Basin: (i) how can we control the sources and processes of anthropogenic pollution and disturbance to foster good governance that prioritizes Yangtze River protection?, and (ii) how can we sustain the Yangtze River ecosystem through integrated multidimensional management?

\section{Ecohydrology for improving the sustainability of the Yangtze River Basin \\ Brief introduction of ecohydrology}

The increasing human population and degradation of the biological integrity of ecosystems have greatly threatened water and ecological security. Ecohydrology offers a holistic approach to this problem, with effective tools for water resource management and governance. The conceptualization of ecohydrology was based primarily on the following starting points: (1) the apparent weakness of traditional approaches to water management, based on a mechanistic vision of freshwater ecosystem functioning, and (2) the unsustainability of the most common approaches, based on civil engineering practices that were increasingly constrained by funding and energy (Zalewski 2002).

The principles of ecohydrology include (Zalewski 2013, 2015) (1) river basin scale as the fundamental framework, (2) enhancement of ecosystem resilience and robustness under anthropogenic stress via holistic management as the target, and (3) innovation and application of ecological engineering as the primary methods. Under the proposed framework of "dual regulation", i.e. the regulation of biota structure and dynamics by hydrology and vice versa, the multidimensional goal of ecohydrology has been integrated into the following areas: water resources, biodiversity, ecosystem services, resilience, and cultural heritage (Zalewski et al. 2016, 2018b).

In recent years, the rapid development of ecohydrology has led to the emergence of new thoughts on integrated water resource management and governance in facing the growing uncertainties and challenges of global change (Allan et al. 2013; Xia 2012; Akhtar et al. 2013; Davies and Simonovic 2011). New questions have been raised in the field of ecohydrology.

\section{How do humans and ecosystems interact under climate change?}

Ecosystem services-i.e. provision, regulation, support, and culture-are the benefits people obtain from ecosystems (Guerry et al. 2015). However, with the expansion of the human population and the development of science and technology, the natural ecosystems at Earth's surface seem to be entirely affected by human influence (Akhtar et al. 2013, 2018). Particularly in the Anthropocene
Epoch, unprecedented anthropogenic activities not only significantly modify ecosystem services but also yield new regimes of human-ecosystem interactions (Akhtar et al. 2013; Davies and Simonovic 2010). Supporting the well-being of humans, ecosystems seem to be increasingly "designed" to sustain human needs while gradually losing their unspoiled or pristine state (Simonovic and Breach 2020; Davies and Simonovic 2011). In particular, to adapt to climate change or to mitigate its adverse effects, new infrastructures or facilities have emerged in human settlements to reduce disaster risks and provide local economic development. One example is the growing need for renewable energy and regulation services, both for flood control and freshwater storage, through dam construction and reservoir creation. While damming campaigns along river channels could provide invaluable support for the above services, freshwater ecosystems could become the largest losers of the Paris Agreement. Therefore, it is of immense significance to balance the trade-offs between sustaining healthy natural ecosystems and supporting human well-being.

\section{Water management or governance? And, what is the bottom line?}

The nouns "management" and "governance" are mostly similar, yet they are indeed slightly different. "Governance" is the strategic task of setting goals, directions, limitations, and accountability frameworks. "Management" is the allocation of available resources and overseeing smooth operations. With respect to water resources, we frequently set various goals to regulate water resources in space and time, e.g. flood control, environmental flow, and water supply (with or without the priority of water quality). Do we manage, or do we govern? Although the theoretical framework of ecohydrology emphasizes the dual regulation between ecosystems and water under multiple dimensions, the questions of how to manage or govern such "dual regulations" and what the status of "dual regulation" should be sustained still need wisdom and case studies. In addition, the "bottom line" (the minimum acceptable level in both spatial and temporal scales) of water resource management or governance is not well defined. What are the "bottom lines" for human wellbeing or sustaining ecosystem functioning? Do they conflict, or could they reconcile?

\section{Towards the eco-water security of the Yangtze River Basin for sustainable development}

The noun "security" is defined as the quality or state of being secure, such as freedom from danger, fear, or anxiety, or freedom from prospect of being laid off. Water security has been well defined as "the capacity of a population to safeguard sustainable access to adequate 
quantities of acceptable quality water for sustaining livelihoods, human well-being, and socioeconomic development, for ensuring protection against water-borne pollution and water-related disasters, and for preserving ecosystems in a climate of peace and political stability" (Braga et al. 2014; Bigas 2013). In general, an ecological security discourse is one that orients towards the resilience of ecosystems themselves, with this in turn enabling the protection of the most vulnerable across time, space, and species (Hough 2017; de Grenade et al. 2016; Cherry 1995). It was initially referred to by the International Institute for Applied Systems Analysis (IIASA) in the late 1980s, who expanded the issue of global security from conventional war to all aspects in human society, including nature, or the ecosystem (IIASA 1989).

Both water resources and ecosystem services provide fundamental support for human well-being in river basins. Here, we propose that eco-water security means ensuring extent for ecosystem, such as forest-grass cover, rivers and lakes, wetlands and coastal zones and human settlements, served for human survival and development demands and linked with water cycling in basin or global, not allow to be damaged and polluted (Xia et al. 2020). Such conceptual combination roots in a secured water resources provision, in both water quantity and quality for both human settlements and also for the ecosystem. "Damaged" water cycling failed in the provision of water to both human and ecosystem, and "polluted" waters limited its use to maintain the good status of both human well-beings and the ecosystem. The eco-water security in river basin has the following principles: (1) river basin scale as the fundamental framework; (2) enhancement of ecosystems resilience and robustness under the anthropogenic stress via holistic management as the target; (3) innovation and application of ecological engineering as the methodologies (Zalewski 2013, 2015).

Such conceptual combination, i.e. eco-water security, has the following highlights providing strategic solutions for the sustainable development of the Yangtze River Basin.

\section{Security is the "bottom line" in all four dimensions}

The term "eco-water security" clearly illustrates that both the ecosystem and water in the Yangtze River shall be secured in terms of all decisions and efforts. According to Zalewski et al. (2018a), there are four relevant dimensions: biodiversity, resilience, ecosystem services, and culture heritage. Security is the fundamental objective of good governance of ecosystems and water in the Yangtze River Basin (Fig. 3). At present, efforts and measures in the Yangtze River, which is the highest-priority river in China, include the following aspects:

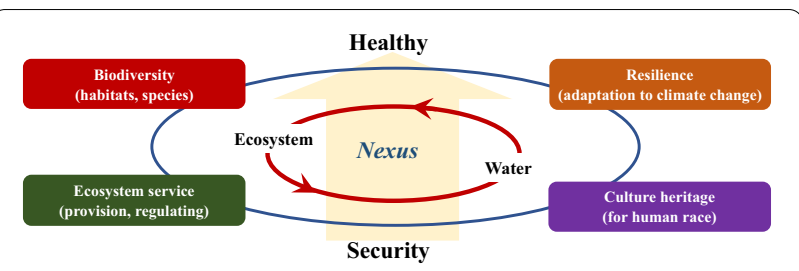

Fig. 3 Conceptual framework of "eco-water security"

1. Identify the potential threats or risks to ecosystems and water cycling under climate change. Such threats or risks originated from an increase in extreme climate events and anthropogenic activities, e.g. the development of human settlements along lake-reservoir shorelines.

2. Protect the availability of water both in quality and quantity for both ecosystem and human settlements. Such measures have included a large campaign of water pollution control and prevention and flood management in the Yangtze River Basin, particularly in urban areas.

3. Implement restoration measures to reduce or stop the drastic decline of biodiversity in the Yangtze River Basin. Such measures include a fishing ban on the Yangtze River and restoration of the fish community by annual artificial release of various fish species into the Yangtze River.

\section{"Healthy" Yangtze is the goal through good governance}

Above the "bottom line" of security, decisions and efforts for river basins would be oriented to the "healthy" status of the Yangtze River ecosystem. The "healthy" Yangtze River is a function of several variables, such as the human population and settlement distribution, socioeconomic development levels, areas of natural reserve for ecological restoration, various human activities, and potential risks to biodiversity. Efforts or measures are needed to prevent deterioration of both ecosystems and water cycling in the Yangtze River Basin. However, more importantly, growing tension between ecological conservation and the need for socioeconomic development requires wisdom in policymaking and governance. It is neither humancentric nor natural-centric, but it seeks an eclectic approach to reconcile the ecological needs and wellbeing of humans under a holistic view, driving the whole social and economic system in the Yangtze River Basin towards a path of green development. Good governance does not merely try to manage the available resources, it provides robust tools or toolboxes for natural-based solutions beyond these resources. 


\section{Yangtze simulator, a model system for eco-water security}

\section{Development of the Yangtze simulator}

Being acutely aware of eco-water security challenges in the Yangtze River Basin and the Yangtze Economic Belt, an eco-environmental campaign, namely, the "Great Protection Strategy of the Yangtze", was initiated in 2016 (Daily 2016), which includes the following major actions: (1) large infrastructure investments in sewage and waste treatment in Yangtze River Basin cities to strengthen pollution control, (2) a 10-year commercial fishing ban on the Yangtze River in a bid to protect its aquatic life, (3) ecological restoration along the shoreline and important wetlands, and (4) optimized water resource allocation and regulation for ecological needs in the Yangtze River Basin.

As an essential technological support to the "Great Protection Strategy of the Yangtze River", the Yangtze Simulator was first proposed by Prof. Jun Xia in 2017, which then immediately received positive responses and was subsequently put into practice. The Yangtze Simulator is not merely a numerical model but an integrated system with functions of observation, monitoring, assessment, modelling, prediction, warning, and decision support. The Yangtze Simulator, supported by big data and artificial intelligence (AI), emphasizes the interactions among upstream, middle stream, and downstream, as well as interdisciplinary research across natural science and social science.

\section{Framework and functions of the Yangtze simulator}

The framework of the Yangtze Simulator includes (Fig. 4):

\section{Observation and monitoring networks}

Over the past decade, hydrology, meteorology, and water environment monitoring in China have made considerable progress, and their online monitoring capability with high precision has been significantly improved. At present, there are thousands of meteorological stations and hundreds of hydrological and water environmental monitoring stations distributed in the Yangtze River Basin, providing real-time hydrological and metrological data supporting modelling and prediction. In addition, socioeconomic and demographic data in the Yangtze River Basin are also included in the Yangtze Simulator database as a supplementary module for decision makers.

\section{Models of hydrology, ecology, and social economy at multiple scales}

The fundamental models of the Yangtze Simulator are hydrological and hydrodynamic models across multiple scales. These models include the full river basin hydrological model, regional hydrological model, particularly in the urban water system, hydrodynamic model in the main stem and major tributaries of the Yangtze River,

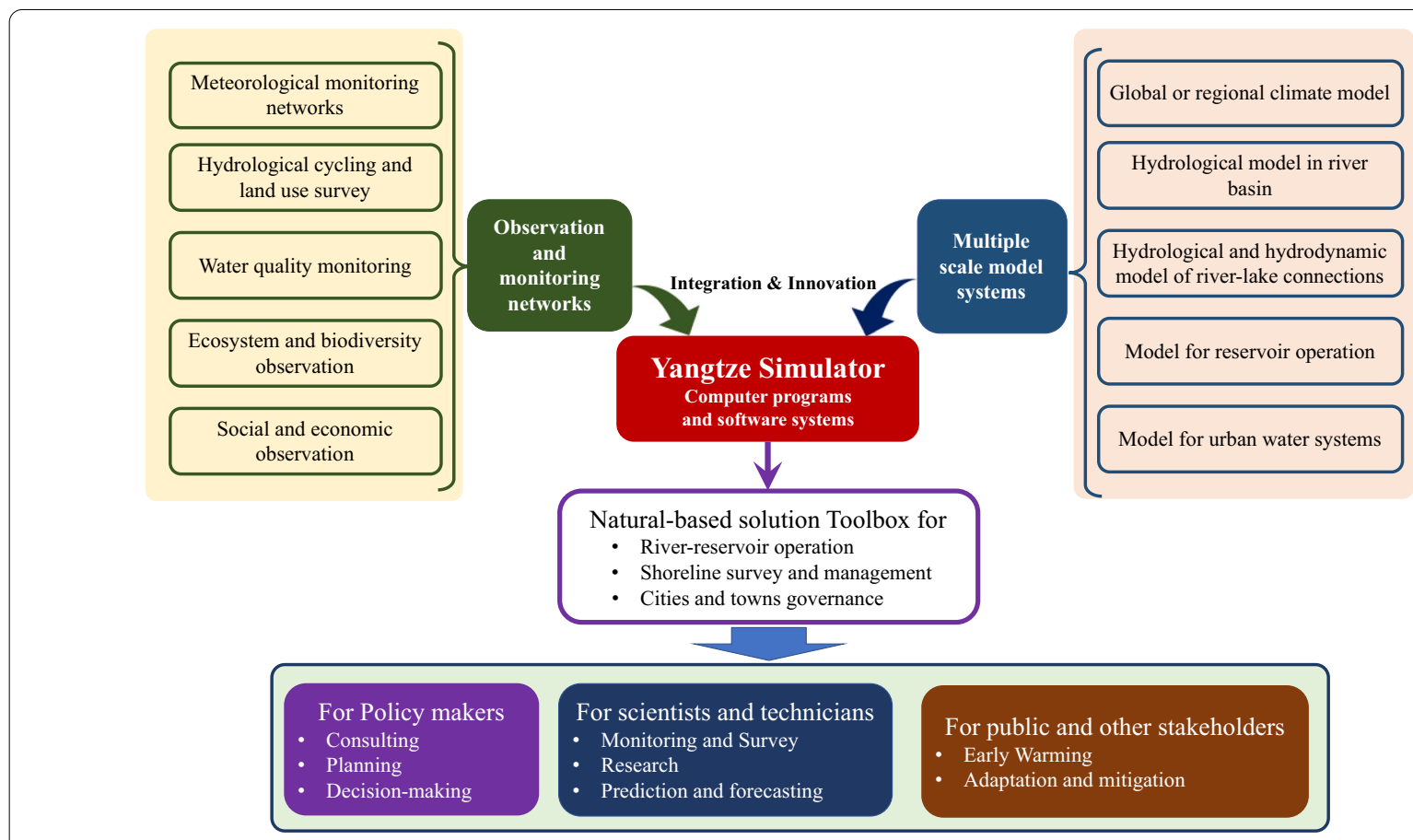

Fig. 4 Framework of the Yangtze Simulator 
and socioeconomic model. Water quality and ecological processes are also incorporated into the modelling work of the Yangtze Simulator. Ecological processes, for example, include the model of food webs in the Yangtze River Basin and the landscape model of vegetation recovery along the shoreline of the Yangtze River. All these models will be docked with regional or global climate models that support further simulations and projections in the Yangtze Simulator.

\section{Integration of multiple-scale models to simulate ecosystem and water cycling}

One critical task of the Yangtze Simulator is to integrate these models into operational and visible simulation systems to model multiple stresses on the ecosystem and water cycling in the Yangtze River Basin. These multiple stresses, or driving forces, include extreme climate events, e.g. regional or full river basin floods or droughts, pollution loads from point or nonpoint sources, and flow regulation by dams or water diversion projects. The Yangtze Simulator will also perform scenario analysis to model the responses of the eco-water nexus to projected changes in multiple stresses or driving forces, providing references or policies for the green development of the Yangtze River Basin.

Under the above framework, the Yangtze Simulator performs the following functions:

1. It offers a platform for integrating data from all aspects of ecosystems and water, as well as socioeconomic development, in the Yangtze River Basin. The big data system collects information from ecosystems and water cycling in the Yangtze River Basin for several decades, not merely demographic and economic statistics. These sources include historical remote sensing data, water quality data, and biodiversity data over the past 4 decades, and meteorological data over the past 5 decades. It attempts to form a "digital twin" background of the historical Yangtze River, which is defined as a virtual representation of the Yangtze River system to enable understanding, learning, and reasoning.

2. Although still under development, the Yangtze Simulator couples a processed-based model and a datadriven model powered by AI. The multiscale model system is expected to provide simulations of the current status of ecosystem and water cycling in the Yangtze River, separate future scenarios of climate change, water regulation and diversion, as well as anthropogenic activities in the river basin.

3. The innovative idea of the Yangtze Simulator offers the opportunity to perform high resolution and timely prediction for stakeholders or policy mak- ers to build future plans, set development goals, or take actions. All these efforts will enable the Yangtze Simulator to perform multiple functions for different users, i.e. the public version, the expert version, and the version for policy makers.

The public version of the Yangtze Simulator offers the basic and encyclopaedic information of the Yangtze River and its reach where the user is located. Such information includes the geomorphological characteristics of nearby Yangtze River main stem and tributaries, an interactive map of land-use and historical land-use changes, socioeconomic data of the nearby cities or towns, hydrological and environment data with assessment results, and prewarning functions. In addition, to respond to public concerns about biodiversity in the Yangtze River Basin, the public version of the Yangtze Simulator offers scientific knowledge of the biodiversity and protection actions undertaken in the Yangtze River Basin. With higher user privileges, the expert version of the Yangtze Simulator offers additional modules for scientists and engineers, enabling real-time hydrology and meteorological and environmental data for analysis. In addition, such an advanced version will provide a "digital twin" model of upstream dams, Yangtze reaches, and shoreline cities (especially mega ones) along the river, reservoir, and lakes. Real-time data will provide scientists and engineers with comprehensive planning for flood control and protection of human settlements, as well as infrastructure planning for pollution control and protection measures of biodiversity in the Yangtze River. In the Yangtze Simulator, the version for policy makers provides the following three functions: (a) historical data series and future predictions of hydrological-environmental-ecological-socioeconomic data with high-resolution land-use and land cover in the Yangtze River Basin (especially the shoreline human settlements, cities, and towns); (b) visual simulations of the Yangtze hydrological-environmental-ecologicalsocioeconomic system under different scenarios, such as extreme climate events, environmental flow regulation, and different planning scenarios for human settlements; and (c) decision-making recommendations for timely decisions by policy makers. In recently years, the Yangtze Simulator is being applied to spatial planning and management on shoreline of the Yangtze River and the sponge city construction, etc. (seen, Xia et al. 2020). It is expected that the Yangtze Simulator could serve as a basic platform for good governance of the Yangtze River Basin. 


\section{Conclusion and perspectives}

The Yangtze River Basin is facing great challenges in its ecosystem and water security under a changing environment. Great protection and green development for the Yangtze River are major issues in China, giving new demands and opportunities for the application of ecohydrology in the Yangtze River Basin. Looking forward to a healthy Yangtze River in the future, it is still a major challenge to implement integrated management of the Yangtze River Basin with regard to water, biodiversity, ecological services, and resilience. The Yangtze Simulator, an integrated model system powered by artificial intelligence and interdisciplinary science, will serve as a robust tool for good government of the Yangtze River.

\section{Acknowledgements}

This research was supported by the Strategic Priority Research Program of the Chinese Academy of Sciences (Grant no. XDA23040304) and National Natural Science Foundation of China (No. 41890823).

\section{Authors' contributions}

JX contributed to the conception of the study and designed research; ZL performed the data analyses and wrote the manuscript; SZ and LZ contributed significantly to analysis and manuscript preparation; DS helped perform the analysis with constructive discussions; DC contributed to the writing and revisions. All the authors read and approved the final manuscript.

\section{Funding}

This study was financially supported by the Strategic Priority Research Program of the Chinese Academy of Sciences (Grant no. XDA23040304), National Natural Science Foundation of China (No. 41890823).

\section{Availability of data and materials}

Not applicable.

\section{Declarations}

\section{Competing interests}

The authors declare that they have no competing interests.

\section{Author details}

${ }^{1}$ State Key Laboratory of Water Resources \& Hydro Power Engineering Sciences, Wuhan University, Wuhan 430072, China. ${ }^{2}$ Institute of Geographical Sciences \& Natural Resources Research, Chinese Academy of Sciences, Beijing 100101, China. ${ }^{3}$ Chongqing Institute of Green and Intelligent Technology, Chinese Academy of Sciences, Chongqing 400714, China. ${ }^{4}$ Colleage of Urban and Environmental Sciences, Northwest University, Xi'an 710127, China.

Received: 24 August 2020 Accepted: 7 April 2021

Published online: 23 April 2021

\section{References}

Akhtar MK, Wibe J, Simonovic SP, MacGee J (2013) Integrated assessment model of society-biosphere-climate-economy-energy system. Environ Model Softw 49:1-21. https://doi.org/10.1016/j.envsoft.2013.07.006

Akhtar MK, Simonovic SP, Wibe J, MacGee J (2018) Future realities of climate change impacts: an integrated assessment study of Canada. Int J Global Warm 17(1):59-88. https://doi.org/10.1504/IJGW.2019.096761

Allan C, Xia J, Pahl-Wostl C (2013) Climate change and water security: challenges for adaptive water management. Current Opin Environm Sustainability 5(6):625-632. https://doi.org/10.1016/j.cosust.2013.09.004

Best J (2019) Anthropogenic stresses on the world's big rivers. Nat Geosci 12(1):7-21. https://doi.org/10.1038/s41561-018-0262-x
Betts HW, Joy C, Haslam W, Hallam AB, Jin XP (2006) Yangtze river flood control and management project-overview and project scope.

Bigas H (2013) Water Security \& the Global Water Agenda: A UN-Water AnaIytical Brief. Institute for Water, Environment \& Health, United Nations University, Hamilton, p 47

Braga B, Chartres C, Cosgrove WJ, Cunha LVD, Gleick P, Kabat P et al (2014) Water and the Future of Humanity: Revisiting Water Security. Springer International Publishing, Berlin

Castello L, Macedo MN (2016) Large-scale degradation of Amazonian freshwater ecosystems. Glob Change Biol 22(3):990-1007. https://doi. org/10.1111/gcb.13173

Chai Y, Li Y, Yang Y, Zhu B, Li S, Xu C et al (2019) Influence of climate variability and reservoir operation on streamflow in the Yangtze River (Article). Sci Rep. https://doi.org/10.1038/s41598-019-41583-6

Chen D, Xiong F, Wang K, Chang Y (2009) Status of research on Yangtze fish biology and fisheries. Environ Biol Fishes 85(4):337-357. https://doi. org/10.1007/s10641-009-9517-0

Chen J, Shi H, Sivakumar B, Peart MR (2016) Population, water, food, energy and dams. Renew Sustain Energy Rev 56:18-28. https://doi.org/10. 1016/j.rser.2015.11.043

Cherry WA (1995). Comments: what is ecological security? Peace Research, 27(2), 87-89. www.jstor.org/stable/23607609.

Daily C (2016) 'Xi stresses 'green development'along Yangtze River'. Chongqing, http://europe.chinadaily.com.cn/china/2016-01/08/content_ 22986291.htm.

Davies E, Simonovic S (2010) ANEMI: a new model for integrated assessment of global change. Interdiscip Environ Rev. https://doi.org/10. 1504/IER.2010.037903

Davies EGR, Simonovic SP (2011) Global water resources modeling with an integrated model of the social-economic-environmental system. Adv Water Resour 34(6):684-700. https://doi.org/10.1016/j.advwatres.2011. 02.010

de Grenade R, House-Peters L, Scott CA, Thapa B, Mills-Novoa M, Gerlak A et al (2016) The nexus: reconsidering environmental security and adaptive capacity (Article). Curr Opin Environ Sustain 21:15-21. https://doi. org/10.1016/j.cosust.2016.10.009

Denman KL, Brasseur G, Chidthaisong A, Ciais P, Cox PM, Dickinson RE et al (2007) Couplings Between Changes in the Climate System and Biogeochemistry. In: Solomon S, Qin D, Manning M, Chen Z, Marquis M, Averyt KB et al (eds) Climate Change 2007: The Physical Science Basis. Contribution of Working Group I to the Fourth Assessment Report of the Intergovernmental Panel on Climate Change. Cambridge University Press, Cambridge, pp 499-587

Di Z, Chang M, Guo P (2019) Water quality evaluation of the Yangtze River in China using machine learning techniques and data monitoring on different time scales (Article). Water. https://doi.org/10.3390/w11020339

Feng LH (2011). Strong signal of the super-huge flood and superposition effect of physical factors-a case study along Yangtze River of China in 1954. Disaster Adv 4(3), 59-63. <Go to ISI>://WOS:000293990400009.

Floehr T, Xiao H, Scholz-Starke B, Wu L, Hou J, Yin D et al (2013) Solution by dilution?-A review on the pollution status of the Yangtze River Environ Sci Pollut Res 20(10):6934-6971. https://doi.org/10.1007/ s11356-013-1666-1

Gu C, Hu L, Zhang X, Wang X, Guo J (2011) Climate change and urbanization in the Yangtze River Delta. Habitat Int 35(4):544-552. https://doi. org/10.1016/j.habitatint.2011.03.002

Guerry AD, Polasky S, Lubchenco J, Chaplin-Kramer R, Daily GC, Griffin R et al (2015) Natural capital and ecosystem services informing decisions: from promise to practice (Review). Proc Natl Acad Sci USA 112(24):7348-7355. https://doi.org/10.1073/pnas.1503751112

Han J, Meng X, Zhou X, Yi B, Liu M, Xiang WN (2017) A long-term analysis of urbanization process, landscape change, and carbon sources and sinks: a case study in China's Yangtze River Delta region (Article). J Clean Prod 141:1040-1050. https://doi.org/10.1016/j.jclepro.2016.09.177

Han X, Feng L, Hu C, Chen X (2018) Wetland changes of China's largest freshwater lake and their linkage with the Three Gorges Dam. Remote Sens Environ 204:799-811. https://doi.org/10.1016/j.rse.2017.09.023

Hough P (2017) Ecological Security. In: Jacob ED (ed) Rethinking security in the twenty-first century: a reader. Palgrave Macmillan US, New York, pp 183-194. https://doi.org/10.1057/978-1-137-52542-0_13 
IIASA (1989) 'Threats to global security: calls for a new initernational diplomacy'R. H. Pry Options. Dec 1989. Austria: International Institute for Applied System Analysis, p. 20.

Krueger T, Hoelzel N, Luckas B (2012) Influence of cultivation parameters on growth and microcystin production of Microcystis aeruginosa (Cyanophyceae) isolated from Lake Chao (China). Microb Ecol 63(1):199-209. https://doi.org/10.1007/s00248-011-9899-3

Le C, Zha Y, LiY, Sun D, Lu H, Yin B (2010) Eutrophication of Lake waters in China: Cost, Causes, and Control. Environ Manage 45(4):662-668. https:// doi.org/10.1007/s00267-010-9440-3

Li Z, Ma J, Guo J, Paerl HW, Brookes JD, Xiao Y et al (2018) Water quality trends in the Three Gorges Reservoir region before and after impoundment (1992-2016). Ecohydrol Hydrobiol. https://doi.org/10.1016/j.ecohyd.2018. 08.005

Li W, Chen J, Li L, Chen H (2020) Land use changes in Yangtze River Basin from 1980 to 2015. Yangtze River 51(2):49-57. https://doi.org/10.16232/j.cnki. 1001-4179.2020.02.010

Liu W, Guo Z, Jiang B, Lu F, Wang H, Wang D et al (2020) Improving wetland ecosystem health in China. Ecol Ind. https://doi.org/10.1016/j.ecolind. 2020.106184

Morgan K, Waretini AF (2013) The Yangtze river: Hydro development, changing geography, cultural and environmental implications. Yangtze River: Geography, Pollution and Environmental Implications (pp. 65-88). https:// www.scopus.com/inward/record.uri?eid=2-s2.0-84892275395\&partn erlD $=40 \&$ md5 =da8f2c308af7b79f 1 bc7de664d019f3b.

Qi W, Mueller B, Pernet-Coudrier B, Singer H, Liu H, Qu J et al (2014) Organic micropollutants in the Yangtze River: Seasonal occurrence and annual loads. Sci Total Environ 472:789-799. https://doi.org/10.1016/j.scitotenv. 2013.11.019

Ramachandra TV, Vinay S, Bharath S, Shashishankar A (2018) Eco-Hydrological footprint of a river basin in Western Ghats. Yale J Biol Med 91 (4), 431-444. $<$ Go to $|S|>: / /$ WOS:0004543336600007.

Ramachandra TV, Vinay S, Bharath S, Chandran MDS, Aithal BH (2020) Insights into riverscape dynamics with the hydrological, ecological and social dimensions for water sustenance. Curr Sci 118(9):1379-1393. https://doi. org/10.18520/cs/v118/i9/1379-1393

Shi H, Chen J, Liu S, Sivakumar B (2019) The role of large dams in promoting economic development under the pressure of population growth. Sustainability. 11(10), 2965. https://www.mdpi.com/2071-1050/11/10/2965

Simonovic SP, Breach PA (2020) The role of water supply development in the earth system. Water. https://doi.org/10.3390/w12123349

Sun C, Shen Z, Liu R, Xiong M, Ma F, Zhang O et al (2013) Historical trend of nitrogen and phosphorus loads from the upper Yangtze River basin and their responses to the three Gorges Dam. Environ Sci Pollut Res 20(12):8871-8880. https://doi.org/10.1007/s11356-013-1859-7

Wang L, Huang Z (2020) What is actually the main cause for the survival crisis of Chinese sturgeon? (Article). Hupo Kexue J Lake Sci 32(4):924-940. https://doi.org/10.18307/2020.0403

Wang PL, Shen H, Xie P (2012) Can hydrodynamics change Phosphorus strategies of diatoms?-Nutrient levels and diatom blooms in lotic and lentic ecosystems. Microb Ecol 63(2):369-382. https://doi.org/10.1007/ s00248-011-9917-5

Wen S, Su B, Wang Y, Zhai J, Sun H, Chen Z et al (2020) Comprehensive evaluation of hydrological models for climate change impact assessment in the
Upper Yangtze River Basin China. Clim Change 163(3):1207-1226. https:// doi.org/10.1007/s10584-020-02929-6

Xia J (2012) Guest editor's introduction. Water Int 37(5):509-511. https://doi. org/10.1080/02508060.2012.729176

Xia J, Zuo Q, Wang G (2020) Ecoydrology. China Sciences Press, Beijing

Xu H, Paerl HW, Qin B, Zhu G, Gao G (2010) Nitrogen and phosphorus inputs control phytoplankton growth in eutrophic Lake Taihu China. Limnol Oceanography 55(1):420-432. https://doi.org/10.4319/lo.2010.55.1.0420

Xu X, Tan Y, Yang G, Barnett J (2018) China's ambitious ecological red lines (Article). Land Use Policy 79:447-451. https://doi.org/10.1016/j.landu sepol.2018.08.037

Xu P, Guo Y, Fu B (2019) Regional impacts of climate and land cover on ecosystemwater retention services in the Upper Yangtze River Basin (Article). Sustainability. https://doi.org/10.3390/su11195300

Yang XK, Lu XX, Ran LS (2016) Sustaining China's large rivers: river development policy, impacts, institutional issues and strategies for future improvement. Geoforum, 69, 1-4. <Go to ISI>://CCC:000370099800001. http://www.elsevier.com.

Yang R, Sun M, Fu B, Zhang L, Zhao W, Zhang Y (2020) Sustainable management strategy of ecosystems in the yangtze river basin (Article). Res Environ Sci 33(5):1091-1099. https://doi.org/10.13198/j.issn.1001-6929. 2020.04.20

Ye X, Zhang Z, Xu CY, Liu J (2020) Attribution analysis on regional differentiation of water resources variation in the yangtze river basin under the context of globalwarming (Article). Water. https://doi.org/10.3390/w1206 1809

Zalewski M (2002) Ecohydrology-The use of ecological and hydrological processes for sustainable management of water resources (Article). Hydrol Sci J 47(5):823-832. https://doi.org/10.1080/02626660209492986

Zalewski M (2013) Ecohydrology: process-oriented thinking towards sustainable river basins. Ecohydrol Hydrobiol 13(2):97-103. https://doi.org/10. 1016/j.ecohyd.2013.06.001

Zalewski M (2015) Ecohydrology and hydrologic engineering: regulation of hydrology-biota interactions for sustainability. J Hydrol Eng 20(1):A4014012. https://doi.org/10.1061/(ASCE)HE.1943-5584.0000999

Zalewski M, McClain M, Eslamian S (2016) New challenges and dimensions of ecohydrology-enhancement of catchments sustainability potential. Ecohydrol Hydrobiol 16(1):1-3. https://doi.org/10.1016/j.ecohyd.2016.01.001

Zalewski M, Arduino G, Bidoglio G, Junk W, Cullmann J, Uhlenbrook S et al (2018a) Low cost, nature-based solutions for managing aquatic resources: integrating the principles of Ecohydrology and the Circular Economy. Ecohydrol Hydrobiol 18(4):309-310. https://doi.org/10.1016/j. ecohyd.2018.12.001

Zalewski M, Fazi S, Wolanski E (2018b) Ecohydrology for water, biodiversity, ecosystem services, and resilience in Africa (Editorial). Ecohydrol Hydrobiol 18(2):93-95. https://doi.org/10.1016/j.ecohyd.2018.03.001

\section{Publisher's Note}

Springer Nature remains neutral with regard to jurisdictional claims in published maps and institutional affiliations.

\section{Submit your manuscript to a SpringerOpen ${ }^{\circ}$ journal and benefit from:}

- Convenient online submission

- Rigorous peer review

- Open access: articles freely available online

- High visibility within the field

- Retaining the copyright to your article

Submit your next manuscript at $\boldsymbol{\nabla}$ springeropen.com 